\title{
Suspected Cases of Corona Virus at Tobruck Medical Center in Eastern Part of Libya
}

\author{
Nasren G. S. Al-Fraik ${ }^{1}$, Miftah S.M. Najem ${ }^{2}$, Khadeejah M. A. Al-Khurum ${ }^{1}$ and Sarah \\ S. Khalleefah ${ }^{3}$
}

${ }^{1}$ Dept. of Pediatric, Fac. of Medical, Tobruck University, Libya.

${ }^{2}$ Dept. of Basic Medical Sciences majoring in Microbiology, Fac. of Medicine, Oral and Dental Surgery, Benghazi University, Libya.

${ }^{3}$ Microbiology Medical Technology Institute, Ajdabiya, Libya.

Received: 25 Feb. 2020 / Accepted 30 March 2020 / Publication date: 20 May 2020

\begin{abstract}
Since December 2019, Corona Virus Disease (COVID-19), a new emerging infectious disease occurred in Wuhan, has spread all over the world and WHO has declared that the infection is "Pandemic" and No country and region can be considered safe. Little is known about the epidemiological and clinical features of pediatric patients with COVID-19. We retrospectively focus on clinical characteristics of suspected cases of covid-19 in pediatric Intensive Care Unit and Pediatric Department at Tobruck medical center in January 2020. 98 children involved in our study, 51\% were females, with age mean $3.286 \pm 3.726$, all patients were Libyan and $82.6 \%$ from Tobruck city. $15.3 \%$ presented with positive family history of same illness, $23.4 \%$ with chronic diseases and $54 \%$ admitted in $1^{\text {st }}$ two weeks of January. $95.9 \%$ presented with dry cough, $75.5 \%$ with shortness of breath, $60.2 \%$ with high grade fever, $24.4 \%$ with headache, $94.8 \%$ with loss of appetite and increasing sleep time in $53 \%$. Lymphopenia was reported in $43.8 \%, \mathrm{C}$ - reactive protein positive in $44.8 \% .73 .4 \%$ treated with cefotaxime followed by $30.6 \%$ azithromycin, ampicillin $25.5 \%$ and cefitriaxone in $15.3 \%$. Steroids was used in $18.3 \%$ of patients. Oxygen therapy was used in $71.4 \%$ of patients. C-x ray with bilateral infiltrations reported in $71.4 \%$, unilateral infiltration in $17.3 \%$. Length of hospital stay was range (1-13 days). $96.9 \%$ of studied children discharged in good general condition. These results may be similar to what is happening in the world and these children may have been infected with covid-19 in the previous January without being diagnosed or suspected. This is may explain why no any case reported in Tobruck city and neighboring cities in Eastern part of Libya.
\end{abstract}

Keywords: Covid-19, Corona virus, Pediatric Intensive Care Unit, Lymphopenia, Outcome.

\section{Introduction}

Corona viruses are non-segmented positive-stranded RNA viruses with a roughly $30 \mathrm{~kb}$ genome surrounded by a protein envelope. Most corona viruses cause diseases in their particular host species (Shi and $\mathrm{Hu}, 2008$ ), those that can infect humans through cross-species transmission have become an important threat to public health. Two serious Corona virus disease outbreaks have happened in the past two decades: severe acute respiratory syndrome (SARS) in 2003 (Donnelly et al., 2003) and Middle East respiratory syndrome (MERS) in 2012 (Cauchemez et al., 2014). In late 2019, an outbreak of pneumonia with unknown etiology was found in Wuhan, Hubei province, China. Then the pathogen was isolated soon and named the 2019 novel corona virus (2019-nCoV) on 12 January 2020 (WHO, 2019a). And on 11 February, the International Committee on Taxonomy of Viruses announced that its official classification is severe acute respiratory syndrome corona virus 2 (SARSCoV-2). The virus spread very fast in Wuhan. Even more unfortunate, as the Chinese Spring Festival is approaching, aggregation of large numbers of people flow caused it to spread quickly across the country and even spread to more than 100 countries (WHO, 2019b). A cohort study of 44672 Chinese cases reported that $2 \cdot 1 \%$ of patients were younger than 20 years, and $1 \cdot 2 \%$ were asymptomatic. (NCPERET, 2020). Pneumonia is the leading cause of mortality in children (Dagan et al., 2011). Despite that all measures has been taken and clearly illustrated by WHO and CDC such measure

Corresponding Author: Miftah S.M. Najem, Dept. of Basic Medical Sciences majoring in Microbiology Fac. of Medicine, Oral and Dental Surgery, Benghazi University, Libya.

E-mail: muftahnajem@gmail.com 
cannot be easily applied and followed within the conflict areas in the world such as Syria, Yemen and Libya which suffers mostly (Daw et al., 2012). Libya has been suffered of a big armed conflict since 2011. The country is divided and two counterattack governments were founded, this has been clearly reflected on the quality of health services all over the country. Influx of immigrants and fighting Militias form all over the world has added extra burdens of traceability and control of emerging infectious diseases in the country (Daw et al., 2016). Tobruck City the second largest city in eastern part of Libya after Benghazi .The geographical area of Tobruck is about 1300 square Kilometers east. It is located $140 \mathrm{KM}$ from the Egyptian border. There outbreak of pneumonia and flu like symptoms happen in Tobruck city in the latest of December 2019 up to end of January 2020. The current study we would like to report on the epidemiological and clinical features of the suspected pediatric cases of corona virus infection in eastern part of Libya in Tobruck City.

\section{Materials and Methods}

These study focusing on clinical characteristics of suspected cases 98 children involved 50femalesand 48 male with age mean $3.286 \pm 3.726$ of covid-19 in pediatric Intensive Care Unit and Pediatric Department at Tobruck medical center (the only hospital in Tobruck City) during January 2020. Data were collected from medical files by authors including age, sex, nationality, residence, family history of $(\mathrm{H} / \mathrm{O})$ same illness, symptoms and signs including cough, fever, headache, loss of appetite, sleeping $\mathrm{H} / \mathrm{O}, \mathrm{H} / \mathrm{O}$ chronic disease, grade of fever, complete blood count (CBC), C-reactive protein (CRP), Chest - $\mathrm{x}$-ray (C-X-ray), and other investigations when available, treatment received, oxygen therapy, complications and outcome. Statistically we used Minitab program version 17. Continuous data are expressed as medians and ranges, and categorical data are presented as counts and percentages.

\section{Results}

Out of 407 child admitted in January 2020, 98 (24\%) children enrolled in our study complaining of respiratory symptoms. Females nearly equaled to males ( $50 \mathrm{~F}$ to $48 \mathrm{M}$ ) as showed in table (1).Age range from 1 month to 14 years with mean $3.286 \pm 3.726$ (fig.1).All of studied patients were Libyan and only $15 / 98(15.3 \%)$ presented with positive family history of same illness, $82.6 \%$ were from Tobruck city. 23/98 (23.4\%) With chronic diseases as listed in table (1). Table (2) showed $53 / 98(54 \%)$ of cases admitted in $1^{\text {st }}$ two weeks of January and there is no big difference in number of cases during $1^{\text {st }}$ and $2^{\text {nd }}$ week.

Table 1: Demographic data of suspected children cases of Corona disease at Tobruck Medical Center in Eastern Part of Libya

\begin{tabular}{|c|c|c|c|}
\hline \multirow[t]{2}{*}{ Demographic data } & & \multicolumn{2}{|c|}{ Children cases of Corona disease } \\
\hline & & Total $(n=98)$ & Percentage $(\%)$ \\
\hline \multirow[b]{2}{*}{ Sex } & Female & 50 & 51 \\
\hline & Male & 48 & 48.9 \\
\hline \multirow{2}{*}{ Residence } & Tobruck & 81 & 82.6 \\
\hline & Periphery & 17 & 17.3 \\
\hline \multirow{2}{*}{ Nationality } & Libyan & 98 & 100 \\
\hline & Non Libyan & 0 & $00 \%$ \\
\hline \multirow{2}{*}{$\begin{array}{l}\text { Family history of same } \\
\text { illness }\end{array}$} & Positive & 15 & 15.3 \\
\hline & Negative & 83 & 84.6 \\
\hline \multirow{2}{*}{ History of chronic diseases } & Positive & 23 & 23.4 \\
\hline & Negative & 75 & 76.5 \\
\hline Age in years & $* 3.286 \pm 3.726$ & & \\
\hline
\end{tabular}




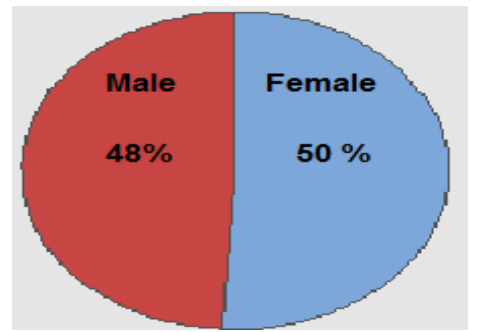

Fig.1: Diagram showing suspected sex distribution in children cases of Corona disease at Tobruck Medical Center in Eastern Part of Libya

Table 2: Distribution of children cases of Corona disease at Tobruck Medical Center in Eastern Part of Libya according to date of admission per week.

\begin{tabular}{ccc}
\hline \multirow{2}{*}{ Week of admission } & $\begin{array}{c}\text { Children cases of Corona disease } \\
\text { Tolal }(\mathbf{n = 9 8 )}\end{array}$ & Percentage (\%) \\
\hline $\mathbf{1}^{\text {st }}$ week & 27 & $27.5 \%$ \\
$\mathbf{2}^{\text {nd }}$ week & 26 & $26.5 \%$ \\
$\mathbf{3}^{\text {rd }}$ week & 23 & $23.4 \%$ \\
$\mathbf{4}^{\text {th }}$ week & 22 & $22.4 \%$ \\
\hline
\end{tabular}

Regarding symptoms and main clinical presentation of patients as listed in table (3),94/98(95.9 $\%$ ) presented with dry cough, 74/98 (75.5\%) with shortness of breath (SOB),82/98 (83.6\%) with fever $(60.2 \%$ of them with high grade fever) as showed in figure (2), 24/98 (24.4\%) with headache, $93 / 98(94.8 \%)$ with loss of appetite and 52/98 (53\%) increasing sleep time than usual sleeping before illness.

Table 3: Clinical characteristics of suspected children cases of Corona disease at Tobruck Medical Center in Eastern Part of Libya

\begin{tabular}{lcc}
\hline & \multicolumn{2}{c}{ Children cases of Corona disease. } \\
Pymptoms and signs & Tolal (n=98) & $95.9 \%$ \\
\hline Cough & 94 & $75.5 \%$ \\
SOB & 74 & $83.6 \%$ \\
Fever & 82 & $24.4 \%$ \\
Headache & 24 & $94.8 \%$ \\
Loss of appetite & 93 & $53 \%$ \\
Increase sleeping time & 52 & $5 \%$ \\
\hline
\end{tabular}

SOB: Shortness of breath

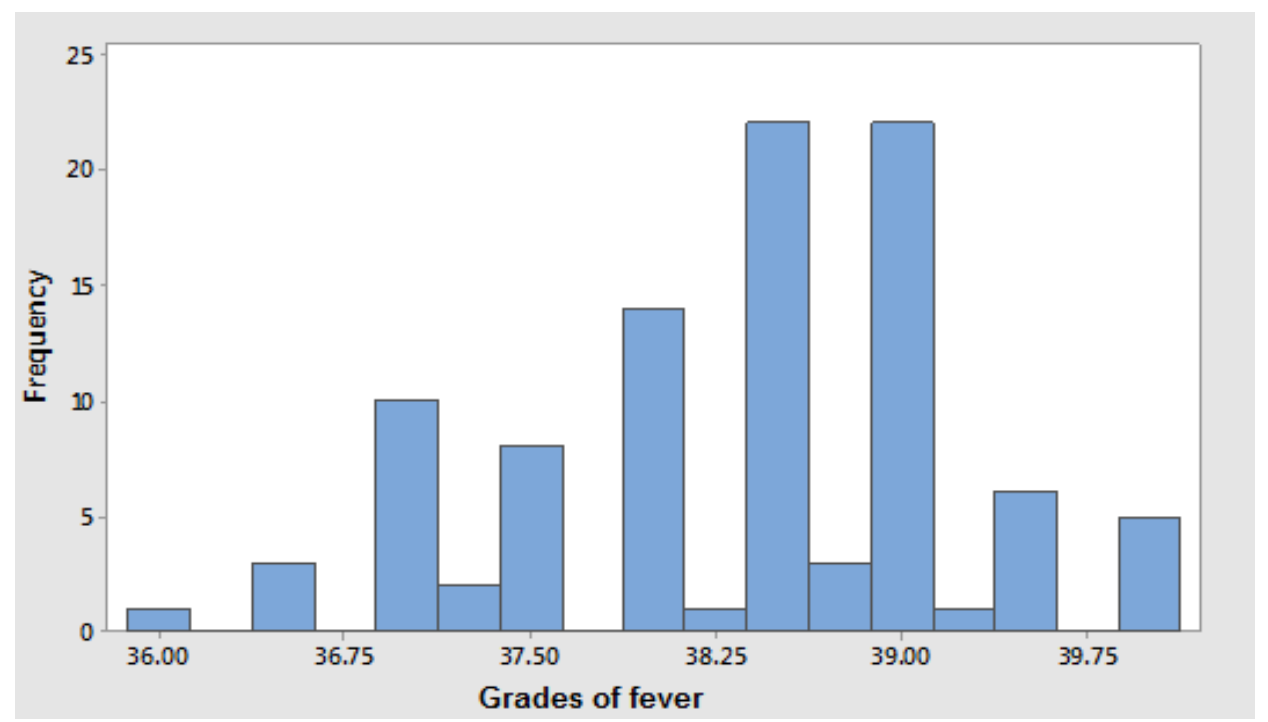

Fig. 2: Histogram showing frequency Grades of fever in children with respiratory problem 
Laboratory data showed in table (4), 11/98(11.2\%) presented with leucocytosis, 14/98 (14.2\%) leucopenic and 73/98 (74.4\%) within normal limit according to age, while 43/98(43.8\%) with lymphopenia, 16/98 (16.3\%) with lymphocytosis and (39.7\%) reported with normal lymphocytes count as showed in figure (3). While neutrophilia reported in 35/98 (35.7\%) of studied children. CReactive Protein (CRP) positive in44/98(44.8 \%), anemia in23/98 (23.4\%) of patients and Red Cell Distribution Width (RDW) mean in patients were 15.569.The main line in treatment as listed in table (5) was antibiotics, cefotaxime $72 / 98$ (73.4 \%) most commonly used followed by azithromycin 30/98 ( $30.6 \%$ ) , ampicillin 25/98(25.5\%) and cefitriaxone 15/98(15.3\%).Steroids was used in 18/98 $(18.3 \%)$ of patients. Oxygen therapy was used either nasally or by mask in 70/98 (71.4\%) of patients and mechanical ventilator not used yet. Chest-x ray (C-x ray) showed bilateral infiltrations in 70/98 (71.4\%), unilateral infiltration in17/98 (17.3\%) and free C-x-ray in $11(11.2 \%)$ as listed in table (6). No complications reported in our patients. Length of hospital stay (LOS) was range (1-13 days) with mean 4.388+2.431days. 95(96.9\%) of studied children discharged in good general condition, 2 patients leaved against medical advice and one patient died was down syndrome with congenital heart disease and sepsis.

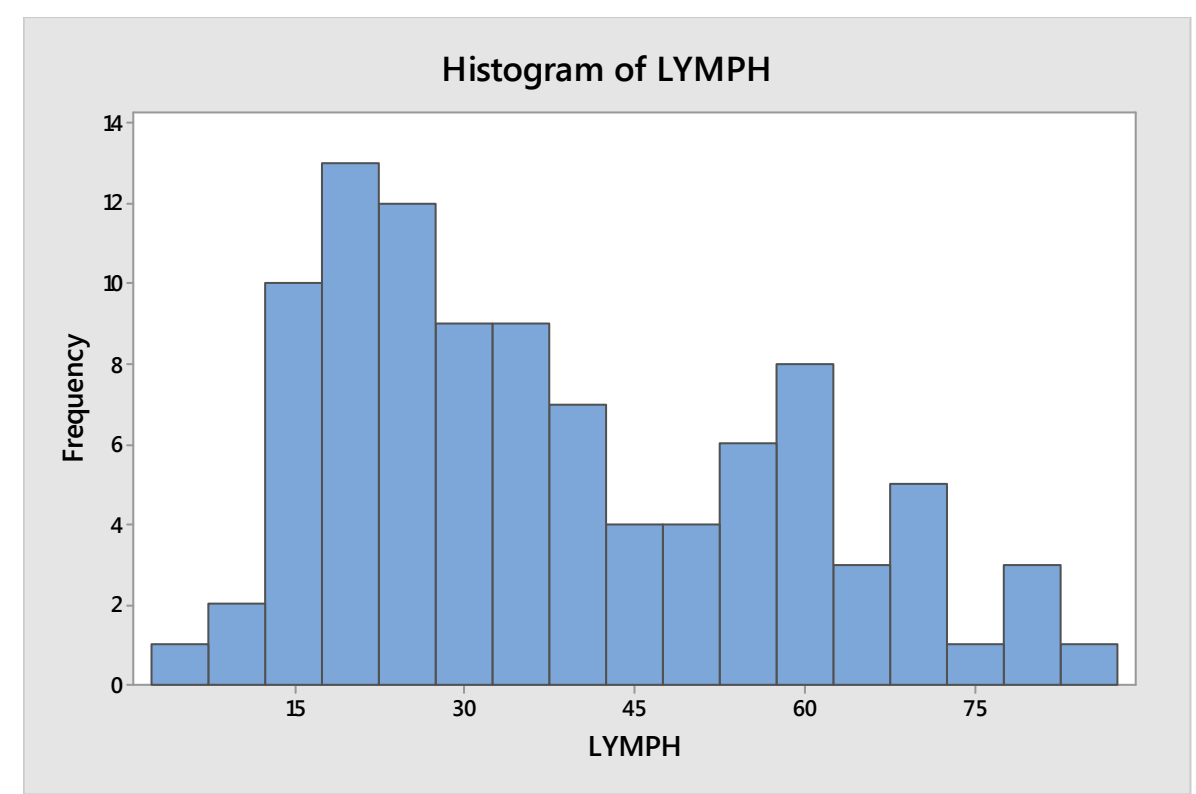

Fig. 3: Histogram showing frequency Lymphocytic counts in studied children in children with respiratory problem

Table 4: Laboratory data in studied group

\begin{tabular}{lc}
\hline Parameter & Mean \pm SD \\
\hline WBC & $9.481 \pm 5.339$ \\
Lymphocytes & $38.15 \pm 19.45$ \\
Neutrophils & $51.32 \pm 18.20$ \\
HB & $11.104 \pm 1.833$ \\
HCT & $32.826 \pm 5.098$ \\
MCV & $73.16 \pm 10.28$ \\
MCH & $26.105 \pm 3.626$ \\
MCHC & $35.236 \pm 2.665$ \\
Platelets & $298.7 \pm 130.4$ \\
RDW & $15.569 \pm 2.478$ \\
\hline
\end{tabular}

WBC: White Cell Count, HB: Hemoglobin, HCT: Hematochrit, MCV: Mean Corpuscular, MCH: Mean congenital heart, MCHC: Mean Corpuscular Hemoglobin Concentration, RDW: Red cell distribution width 
Table 5: Treatment regimens

\begin{tabular}{lcc}
\hline Treatment line & Route & Used in \% \\
\hline Cefotaxime & IV & $73.4 \%$ \\
Azithromycin & Oral & $30.6 \%$ \\
Ampicillin & IV & $25.5 \%$ \\
Cefitriaxone & IV & $15.3 \%$ \\
Steroids & IV & $18.3 \%$ \\
Oxygen & Nasal prong \& Mask & $71.4 \%$ \\
\hline
\end{tabular}

Table 6: Chest x-ray findings in our patients

\begin{tabular}{lcc}
\hline Finding & No. & \% \\
\hline Bilateral infiltration & 70 & $71.4 \%$ \\
Unilateral infiltration & 17 & $17.3 \%$ \\
Free & 11 & $11.2 \%$ \\
\hline
\end{tabular}

Table 7: Outcome

\begin{tabular}{lcc}
\hline Outcome & No. & \% \\
\hline Discharged & 95 & $96.9 \%$ \\
LAMA & 2 & $2 \%$ \\
Died & 1 & $1 \%$ \\
\hline
\end{tabular}

\section{Discussion}

Corona viruses are a large family of viruses that are known to cause illness ranging from the common cold to more severe diseases. No studies done on children with suspected COVID 19 in Libya. Of particular concern, our study found that most the children were suspected with COVID 19 were from TobruckCity, with mean age $3.286 \pm 3.726$ years, and $51 \%$ were females. While in other study $36(5 \%)$ were in children with Covid 19 (aged $1-16$ years; mean age $8 \cdot 3$ [3.5] years) and 13 $(36 \%)$ of 36 patients were female (Qiu et al., 2020). Family history positive in $15.3 \%$ of patients in this study. Cough, SOB, fever and loss of appetite are the main clinical presentations of suspected cases. By contrast with other studies done on children with positive COVID 19, first study showed only one child has mildcough and two children have a mild fever $\left(37.4-38.5^{\circ} \mathrm{C}\right)$. None of the nine children required intensive care or mechanical ventilation or had any severe complications (Liang et al., 2020). This agree with our study which reported no child need mechanical ventilation support. Another study showed fever (13 [36\%]) and dry cough (seven [19\%]). Of 13 patients with fever, four $(11 \%)$ had a body temperature of $38 \cdot 5^{\circ} \mathrm{C}$ or higher and nine $(25 \%)$ had a body temperature of $37 \cdot 5-$ $38.5^{\circ} \mathrm{C}$. Other symptoms were recorded infrequently, includingsore throat (two [6\%]), pharyngeal congestion (one [3\%]), dyspnoea or tachypnoea (one [3\%]) (Qiu et al., 2020).On another hand another study done on adult with COVID 19 showed The most common symptoms at onset of illness were fever in $48(77 \%)$ patients, cough in $50(81 \%)$, headache in $21(34 \%)$, myalgia or fatigue in 32 $(52 \%)$, diarrhea in $3(8 \%)$, and haemoptysis in $2(3 \%)$. Only two patients $(3 \%)$ developed shortness of breath on admission (Xiao-Wei et al., 2020).

Regarding laboratory data $43.8 \%$ of children with+ Ve COVID 19 reported with lymphopenia as showed in (Liang et al., 2020) and $88.9 \%$ of children had normal or decreased white blood cell counts, consistent with the main characteristic of viral infection. Also in another study was showed decreased lymphocytes in (11 [31\%]), leucopenia in (seven [19\%]) of children(11). While in this study 11/98(11.2\%) presented with leucocytosis, 14/98(14.2\%) leucopenic and 73/98 (74.4\%) within normal limit according to age, while 43/98(43.8 \%) with lymphopenia, 16/98(16.3 \%) with lymphocytosis and $(39.7 \%)$ reported with normal lymphocytes count.

CRP positive in $44.8 \%$.in current study. While in another study all inflammatory indicators, including CRP, PCT (procalcitonin), ESR (erythrocyte sedimentation rate) and IL-6 (interleukin 6) were all within the normal range (Liang et al., 2020).

Cefotaxime and azithromycin are the most common used antibiotics, many protocols advised to use azithromycin in management of patients with COVID 19. Most adultpatients in another study received antiviral treatment with interferon alpha inhalation ,lopinavir and ritonavir, and arbidol . Patients received treatment with corticosteroid (and gamma globulin (Xiao-Wei et al., 2020). Steroids used in $18.3 \%$ in our study.71.4\% need oxygen supply in PICU in Tobruck Medical Center and 
without any need to mechanical ventilation. While in another study $17 \%$ needed oxygen inhalation (Qiu et al., 2020). Imaging showed bilateral infiltrations in chest $\mathrm{x}$-ray in $71.4 \%$ of suspected children in current study and unilateral infiltration in $17.3 \%$. While in another study one (11.1\%) boy showed pulmonary consolidation and ground glass opacity on the first day .Five other (55.6\%) children showed no abnormal chest radiograph (Liang et al., 2020).

Also in generally, two types of abnormal radiographic presentations were seen: multiple opacities and patchy opacities.19 (53\%) pediatric patients had pulmonary ground-glass opacities (Qiu et al., 2020). In study done on adult, (84\%) patients showed bilateral involvement on chest radiographs (Xiao-Wei et al., 2020) $96.9 \%$ of children discharged without any complications \& LOS in this study was range (1-13 days) with mean 4.388+2.431 days like (Qiu et al., 2020) all children with COVID 19 discharged and cured and the mean number of days in hospital was 14 days. Until April 2020 no cases of COVID 19 discovered in Tobruck and neighboring cities in Eastern part of Libya like Darna, Al Beda, Al Marg and only four cases from the same family in Bengasi.

\section{Conclusion \& Recommendations}

In this study at January 2020, 24\% of admission in PICU \& Pediatric department due to respiratory illness, clinical presentations, laboratory data, imaging nearly matched with what happen in the world and may be due to COVID 19. The obtained may be similar to what is happening in the world and these children may have been infected with covid-19 in the previous January without being diagnosed or suspected and herd immunity already acquired in Tobruck city. The farther studies recommend on adults and children in Tobruck city and neighboring cities, and recommend to screen the suspected cases for COVID 19 IgG.

\section{References}

Cauchemez, S., C. Fraser, M.D. Van Kerkhove, et al., 2014. Middle East respiratory syndrome coronavirus: quantification of the extent of the epidemic, surveillance biases, and transmissibility. Lancet Infect Dis., 14: 50-56.

Dagan, R., Z.A. Bhutta, C.A. de Quadros, et al., 2011. The remaining challenge of pneumonia: the leading killer of children. Pediatr Infect Dis J., 30: 1-2.

Daw, M.A., A.H. El-Bouzedi and A.A. DauTrends, 2012. Patterns of deaths, injuries and intentional disabilities within the Libyan armed conflict., 2017PLoS O

Daw, M.A., A. El-Bouzedi, M.O. Ahmed, A.A. Dau, and M.M. Agnan, 2016. Epidemiology of hepatitis $\mathrm{C}$ virus and genotype distribution in immigrants crossing to Europe from North and sub-Saharan Africa Trav. Med. Infect Dis., 14 (5) (Sep 1):517-526.

Donnelly ,C.A., A.C. Ghani , G.M. Leung, et al., 2003..Epidemiologicaldeterminants of spread of causal agent of severe acute respiratory syndrome in Hong Kong. Lancet, 361: 1761-66.

Liang, S.U., M. Xiang, Y.U. Huafeng, Z. Zhaohua, B. Pengfei, H. Yuling, S. Jing, L. Yanqin, Y. Chun, G. Jin, Z. Zhongfa and G. Zhongtao, 2020. The different clinical characteristics of corona virus disease cases between children and their families in China- the character of children with COVID-19, Emerging Microbes \& Infections, 9:1, 707-713, DOI: 10.1080 /22221751.2020.1744483

Novel Coronavirus Pneumonia Emergency Response Epidemiology Team, (NCPERET), 2020. .The epidemiological characteristics of an outbreak of 2019 novel coronavirus diseases (COVID-19) in China. Zhonghua Liu Xing Bing Xue Za Zhi, 41: 145-51

Qiu, H., J. Wu, H. Liang, L. Yunling, Q. Song, D. Chen, 2020..Clinical and epidemiological features of 36 children with coronavirus disease 2019 (COVID-19) in Zhejiang, China: an observational cohort study. Lancet Infect Dis; published online March 25.https://doi.org/10.1016/S14733099(20)30198-5.

Shi, Z. and Z. Hu, 2008. A review of studies on animal reservoirs of the SARS coronavirus. Virus Res., 133: 74-87.

World Health Organization, (WHO), 2019a. Coronavirus disease (COVID-2019) situation reports. Available from: https://www.who.int/docs/default-source/coronaviruse/situation-reports 2020 0310-sitrep-50-covid-19.pdf? Sfvrsn=55e904fb_2. 
World Health Organization, (WHO), 2019b. Novel coronavirus (2019 nCoV). Geneva, Available, https://www.who.int/emergencies/diseases/novelcoronavirus

Xiao-Wei, X. , W. Xiao-Xin, J. Xian-Gao, X. Kai-Jin, Y. Ling-Jun, M. Chun-Lian, L. Shi-Bo, W. Hua-Ying, Z. Sheng, G. Hai-Nv, S. Ji-Fang, C. Hong-Liu , Q. Yun-Qing, and L. Lan-Juan, 2020..Clinical findings in a group of patients infected with the 2019 novel coronavirus (SARSCov-2) outside of Wuhan, China: retrospective case series, BMJ; 368:m606 http://dx .doi.org/10.1136/bmj.m606 